\title{
Relationship between ADHD Markers and Self-Perceived Stress: Influences on Academic Performance in Preadolescents
}

\author{
Carlos Valiente-Barroso ${ }^{1}$ \\ ${ }^{1}$ Department of Basic Psychology II (Cognitive Processes), Complutense University of Madrid, Madrid, Spain \\ Correspondence: Dr. Carlos Valiente-Barroso, C/General Dávila 224-E, 3ํㅡ, 39006 Santander, Cantabria, Spain. \\ Tel: 34-629-412-912. E-mail: carlosvbsiete@hotmail.com
}

Received: September 25, 2013

Accepted: October 12, 2013 Online Published: October 18, 2013

doi:10.5539/jedp.v3n2p193

URL: http://dx.doi.org/10.5539/jedp.v3n2p193

\begin{abstract}
The symptoms associated with Attention Deficit with Hyperactivity Disorder (ADHD), included in its different specific subtypes involves cognitive, emotional and behavioral changes leading to relationship and learning difficulties in school settings. Likewise, the impact of stress on academic performance, perceived by the students themselves on various life aspects, has been detected. A sampling of primary school pupils underwent the following tests: Testing Perception of Differences (Faces-R), Children Daily Stress Inventory (CDEI), and Assessment of Attention Deficit Hyperactivity Disorder (ADHD). At the same time, the academic outcomes provided were gathered by the education center management team by selecting Mathematics and Spanish Language grades as curricular points of reference. Among the data gathered, we can stand out the correlation among the different stress indexes and ADHD symptoms estimated from teachers and gathered from objective parameters. At the same time, the relation of these factors over academic performance is therefore confirmed. Finally, the attention estimation data validate the judgment rendered by teachers, which is consistent with the objective performance shown by pupils.
\end{abstract}

Keywords: academic performance, attention deficit with hyperactivity disorder, childhood development, executive function, stress

\section{Introduction}

\subsection{Attention Deficit with Hyperactivity Disorder}

The Attention Deficit with Hyperactivity Disorder (ADHD) is the most common neuro-behavioral pathology in childhood, with a generally accepted incidence of about $5 \%$ in populations of school children (Polanczyk, de Lima, Lessa-Horta, Bierderman, \& Rohde, 2007), appearing more frequently in the male gender, at a proportion of 3/1 (Valdizán, Mercado, \& Mercado-Undanivia, 2007). Clinically, it is characterized by a persistent pattern of inattention, hyperactivity and impulsiveness, that must appear prior to age 7, in more than one setting (home, school, etc.), and during a period of 6 months or longer. These traits interfere with the child's social and academic activities, or with the occupational activities of the adolescent or adult (American Psychiatric Association, 2013), since it persists as a chronic disorder in $75 \%$ of cases.

The different signs and symptoms of ADHD, with varying presence/absence of the dimensions of inattention and hyperactivity/impulsiveness, give rise to three diagnostic labels. The Diagnostic and Statistical Manual of Mental Disorders (American Psychiatric Association, 1994), describes three subtypes: predominantly inattentive (ADHD-I), predominantly hyperactive-impulsive (ADHD-H) and the two combined (ADHD-C). The same primary symptoms for ADHD that are used as in DSM-IV are used in the DSM-5 to diagnose ADHD. They continue to be divided into two major symptom domains: inattention and hyperactivity/impulsivity (American Psychiatric Association, 2013; Grohol, 2013).

The etiology of ADHD is complex, including several spectrums of potential causes, and resulting explanatory possibilities: genetic (Faraone, et al., 2005; Link et al., 2013), neuro-anatomical (Soliva-Vila, 2006; Emond, Joyal \& Poissant, 2009), neuro-psychological (Castellanos, 1997; Wasserman \& Wasserman, 2012), neuro-chemical (Barkley, 1997; Minzenberg, 2012) and environmental (Biederman, 2005).

The expression of ADHD involves cognitive, emotional, behavioral and motivational disorders (Albert, López-Martín, Fernádez-Jaén, \& Carretié, 2008). For example, cognitive dysfunctions include deficits in 
response inhibition, working memory, and temporal and spatial processing (Barkley, 2006; Alderson, Kasper, Hudec \& Patros, 2013; Kalanthroff, Naparstek \& Henik, 2013), while affective dysfunctions involve difficulty in reward processing, delay intolerance and difficulty in emotional processing and regulation (Nigg \& Casey, 2005; Factor, Rosen \& Reyes, 2013).

The symptomatology associated with ADHD makes a significant impact on the child's family, social and academic environment. Thus we find comorbidity with other disorders and/or impairments, such as substance abuse and Behavior Disorders, along with academic difficulties (Brown, 2005; Cak, Dinc, Tuzun, Evinc, Cop, Cuhadaroglu Cetin, 2013). In this regard, starting school and the ongoing process as a student are usually stressful events, putting students with ADHD in a vulnerable position for experiencing stress.

\subsection{Childhood Stress}

The study of stress that is experienced prior to adulthood has received increasing attention in research, since it can be considered to be an important variable during child and adolescent development (Vanaelst, De Vriendt, Huybrechts, Rinaldi, \& De Henauw, 2012); high levels of daily stress have been associated with significant negative consequences of emotional maladjustment and psychopathology (Jose \& Ratcliffe, 2004; Lupien, McEwen, Gunnar \& Heim, 2009). Furthermore, daily stress apparently makes a more negative impact on the child or adolescent's emotional development than does stress due to life events or chronic stressors (Seiffge-Krenke, 2000; Wagner, Compas, \& Howell, 1988). The term "daily stress" includes those frustrating demands and annoyances that are a part of daily interaction with the environment (Kanner, Coyne, Schaefer, \& Lazarus, 1981; Vanaelst et al., 2012). Such events or circumstances have high frequency, low intensity and high predictability (Seiffge-Krenke, 2007).

If we look at the structure of studies to date, we find that they examine certain areas of stressors that can threaten childhood development, such as:

a) stress due to health, including situations with illness and medical procedures (Bailly, Wertz, Devos, Veignie, \& Turck, 2004; Fernández \& López, 2006) and events having to do with a concern about one's body image (Moulds, 2003; Seiffge-Krenke, 2007);

b) academic stress, comprising stressful events in the academic realm, such as excessive school work, problems interacting with the teacher, learning disabilities and low academic grades (Govaerts \& Grégoire, 2004; Kouzma \& Kennedy, 2004; Hanson et al., 2012), as well as difficulties in peer relations, such as lack of other acceptance, fights, ridicule situations, competitiveness and envy with regard to academic achievements (Lau, 2002; Oros \& Vogel, 2005); and

c) family stress, composed of negative events in the family domain, such as financial difficulty (Duncan, Brooks-Gunn, \& Klebanov, 1994) and a lack of parental supervision or physical solitude (Lau, 2002).

Different studies have shown that these three sources of stress are not independent entities, but they have reciprocal influences (Flook \& Fligni, 2008; Lehman \& Repett, 2007). These in turn have proven to have negative repercussions on school adaptation and academic performance (Bailly et al., 2004; Escobar, Trianes \& Fernández-Baena, 2008; Flook \& Fligni, 2008; Trianes, Blanca, Fernández-Baena, Escobar, Maldonado, \& Muñoz, 2009).

Our study seeks to explore the repercussions of the child's perceived stress factors on academic performance in core subjects such as mathematics and language arts, as well as the influence of clinical signs associated with $\mathrm{ADHD}$, as identified by the homeroom teacher and also detected through objective parameters.

In this manner, our intent is to: a) compare teachers' impressions of signs of ADHD in their students with objective parameters linked to this pathology, such as attention level and impulse control; b) look for a possible relation between ADHD traits - subjective appraisal vs. objective markers - and the student's experience of stress; c) analyze the potential influence of the two factors- ADHD and daily stress — on academic performance.

\section{Materials and Methods}

The sample was composed of 52 students ( 30 boys and 22 girls) who were part of the third, fourth, fifth and sixth grades of a primary school in the region of Cantabria (Spain). Ages ranged from 8 to 11 years (Mean: 9.61, SD: $1.15)$.

Information was collected in compliance with requirements for anonymity and the consent of legal guardians. The process took place during regular school hours over the academic year 2012-13, after receiving permission from the school's administrative team.

In order to collect the information needed for our objective, the following tests were used: 
Evaluación del Trastorno por Déficit de Atención con Hiperactividad (EDAH) [Evaluation of Attention Deficit with Hyperactivity Disorder]. Developed by Farré and Narbona (2010), it assesses attention deficit with hyperactivity (ADHD) by collecting information about the usual behavior of children between the ages of 6 and 12 . For this purpose, it offers the teacher a structured method of observation, consisting of 20 easily understood items that produce scores on 4 scales: Hyperactivity, Attention Deficit, Hyperactivity with Attention Deficit, and Behavior Disorder that may coexist with the syndrome. This test presents reliability coefficients of 0.90 or more for all its subscales.

Perception of Differences Test (FACES-R). Designed by Thurstone and Yela (2012), this test assesses the aptitude to quickly and correctly perceive similarities and differences in partially ordered stimulation patterns. The task consists of determining which of the three faces presented in each element is different from the other two, measuring perception and attention aptitudes through 60 graphic items that consist of faces sketched with basic strokes. Results are expressed in terms of the numbers of right and wrong choices, as well as an Impulse Control Index (ICI), based on the former. In this case, the Cronbach alpha indicates an internal consistency of 0.91 .

Inventario de Estrés Cotidiano Infantil (IECI) [Childhood daily stress inventory]. Developed by Trianes, Blanca, Fernández-Baena, Escobar, and Maldonado (2011), the inventory focuses on assessing stress stimuli and the responses - whether psycho-physiological, emotional, cognitive or behavioral - that are produced in childhood when one is acted on by these stressors. Consequently, it provides a total score for Daily Stress, along with three partial scores: Health and Psychosomatic Problems, Stress in the School Setting, Stress in the Family Environment. There are 22 Yes/No items that describe the occurrence of different events, problems, demands, worries and annoyances that originate in daily interaction with the environment, that may provoke an emotional reaction and may negatively affect the development of school age children. The alpha coefficient for internal consistency, for the total stress index, had a value of 0.81 .

Additionally, data on academic performance was collected from information provided by the school administration, from which we selected the Mathematics and Language Arts grades as having the most weight.

Data analyses were performed with SPSS version 15.0, using central trend measures, Pearson correlation analysis, and the $t$ test for two independent samples.

\section{Results and Discussion}

Table 1 shows descriptive statistics for grades in Mathematics and Language Arts, as well as the indices that were determined from scores on the different tests.

Table 1. Descriptive statistics of the study variables

\begin{tabular}{lllll}
\hline & Mean (SD) & Range & Asymmetry & Kurtosis \\
\hline Mathematics & $6.78(1.70)$ & $2.00-9.00$ & -.664 & .142 \\
Language & $6.55(1.36)$ & $3.00-9.00$ & -.343 & .185 \\
Hyperactivity & $4.59(1.12)$ & $0.00-15.00$ & .789 & -.623 \\
Attention Deficit & $5.52(4.13)$ & $0.00-15.00$ & .585 & -.748 \\
Behavior Disorder & $5.35(6.15)$ & $0.00-26.00$ & 1.598 & 2.245 \\
Stress due to health & $2.05(1.84)$ & $0.00-6.00$ & .285 & -1.261 \\
Academic Stress & $1.75(1.43)$ & $0.00-7.00$ & 1.155 & 2.039 \\
Family Stress & $1.13(1.22)$ & $0.00-4.00$ & .674 & -.683 \\
Total Stress & $4.94(3.31)$ & $0.00-12.00$ & .254 & -.942 \\
Impulse Control Index & $91.50(13.71)$ & $35.00-100.00$ & -2.672 & 8.368 \\
Attention efficacy & $30.62(8.22)$ & $10.00-50.00$ & -.326 & .089 \\
\hline
\end{tabular}

We applied the $t$ test for independent samples in order to discover any possible gender difference with respect to the study parameters. Levene's test (F) was used to analyze the equality of variances (equality for a statistic greater than .05); the confidence interval for means was $95 \%$. Thus, with regard to academic performance, we find higher scores for the girls $(t=2.136, \mathrm{p}=.038)$, with difference of means of .045 (lower) and 1.487 (higher). Regarding mathematics scores, the girls obtained a mean of 7.22 (SD: 1.68), while the boys obtained a mean of 
6.46 (SD: 1.67), though the figures were not statistically significant. As for the rest of the factors studied, the male subjects obtained higher scores in Hyperactivity $(t=2.773, \mathrm{p}=.008)$, with difference of means of 912 (lower) and 5.716 (higher), and in Behavior Disorder $(t=3.163, \mathrm{p}=.003)$, with difference of means between 1.687 and 7.607, consistent with what could be expected from prior studies (Valdizán, et al., 2007). As for the remaining study variables, we did not find any statistical significance in results according to gender.

Focusing on the first specific objective, we analyzed the diagnostic impressions of the teachers from each grade. Although pupils had not been diagnosed for ADHD, based on the systematic behavior assessment (EDAH) drawn from teacher judgments, the percentiles seen in a substantial number of students indicate a reasonable probability of the incidence of this pathology in the classroom. According to the test's normative tables (Farre \& Narbone, 2010) that indicate moderate risk (MR) for percentiles of 90-94, and high risk (HR) for percentiles of 95-100, after balancing the sample for gender and age, we found: 5 students at MR and 8 at $\mathrm{HR}$ for $\mathrm{H} ; 5$ students at MR and 5 at $\mathrm{HR}$ for $\mathrm{AD} ; 3$ students at MR and 3 at $\mathrm{HR}$ for $\mathrm{BD}$; and, 3 students at MR and 6 at $\mathrm{HR}$ for H-AD.

This result may represent deficient diagnosis of this neuro-developmental pathology, with the subsequent lack of adequate treatment. Alternatively, it may point to a "false positive" phenomenon where teachers' diagnostic labeling is often inaccurate, overextending the ADHD categorization to many students who indeed are more restless and/or difficult than the rest of the class. Different sources seem to corroborate the second option, and clinical overdiagnosis of ADHD is found even among primary care pediatricians (Morán Sánchez, Navarro-Mateu, Robles Sánchez, \& Concepción Salesa, 2008), despite being clinically trained specialists that are better prepared to assess this disorder.

However, along with this result based on the experienced judgment of teachers, we checked for agreement between these impressions and the objective parameters offered by the FACES-R test. As one might expect (see Table 2), the three indices estimated (H, AD and BD) showed a correlation among themselves $(p<.01)$. Results obtained for $\mathrm{H}$ did not show any relation to objective data on attention efficacy and impulse control. However, a significant correlation was confirmed between the objective and subjective attention parameters, that is, between attention efficacy (EFF) and estimated attention deficit (AD).

Table 2. Correlation between ADHD traits, self-reported stress and attention capacity

\begin{tabular}{|c|c|c|c|c|c|c|c|c|c|c|}
\hline & 1 & 2 & 3 & 4 & 5 & 6 & 7 & 8 & 9 & 10 \\
\hline 1. Hyperactivity & 1.00 & & & & & & & & & \\
\hline 2. Attention Deficit & $.579 * *$ & 1.00 & & & & & & & & \\
\hline 3. Behavior Disorder & $.735^{* *}$ & $.609 * *$ & 1.00 & & & & & & & \\
\hline 4. Stress due to health & -.151 & .059 & .048 & 1.00 & & & & & & \\
\hline 5. Academic Stress & .241 & $.588 * *$ & $.308^{*}$ & .250 & 1.00 & & & & & \\
\hline 6. Family Stress & -.076 & $.279 *$ & -.001 & .258 & $.443 * *$ & 1.00 & & & & \\
\hline 7. Total Stress & -.005 & $.393 * *$ & .161 & $.759 * *$ & $.736^{* *}$ & $.704 * *$ & 1.00 & & & \\
\hline 8. Age & .137 & .120 & .008 & -.091 & -.047 & -.018 & -.077 & 1.00 & & \\
\hline 9. Impulse Control Index & -.260 & -.273 & -.231 & .116 & -.256 & $-.281^{*}$ & -.151 & .163 & 1.00 & \\
\hline 10. Attention efficacy & -.179 & $-.390 * *$ & $-.316^{*}$ & .005 & $-.356^{*}$ & -.195 & -.225 & $.444^{* *}$ & $.344 *$ & 1.00 \\
\hline
\end{tabular}

Strictly speaking, the lack of agreement on the $\mathrm{H}$ result with respect to analogous results in AD and EFF, does not manifest a lack of diagnostic skill on the part of teachers, since different variables are being measured; these represent the different factors that justify typological variants of ADHD (American Psychiatric Association, 1994). Moreover, the correlation between the EFF and AD data would indicate substantial accuracy in the teachers' impressions. Thus, despite the notable incidence of false positives (Morán Sánchez et al., 2008), different studies defend the effectiveness (and healthcare savings) associated with the impressions of teachers and family members, based on the child's expressed behaviors. Validity and reliability studies to establish the consistency of the ADHD diagnosis in the child population have found this consistency to be high when structured interviews and scales are applied through parents and teachers (Orvaschel, Lewinsohn, \& Seeley, 1995). 
In any case, in order to maximize rigor and accuracy, we insist on the importance of a global diagnostic approach, by which data collected through observation are complemented with external evidence from neuro-psychological, genetic and neurological tests (Faraone et al., 2005; Soliva-Vila, 2006; Link et al., 2013; Emond et al., 2009; Wasserman \& Wasserman, 2012; Minzenberg, 2012).

Next, we inquired into a possible relationship between traits of ADHD - subjective estimation and objective markers - and the student's experience of stress. Generally speaking, we discovered high reactivity to stress in correlation with behavior traits linked to ADHD (see Table 2), as seen in other studies that associate this pathology with a certain style of responding to stress (Bakker, Rubiales \& López, M, 2012). The strongest correlations were found between $\mathrm{AD}$ and family stress (FS), school stress (SS) and total stress (TS), whereas these three (FS, SS, and TS) showed no correlation with $\mathrm{H}$. This result is consistent with studies that have found a high response to stress in children with ADHD-I, predominantly inattentive, as compared to children with ADHD-C (inattention and hyperactivity), who were less reactive; this fact would allude to low reactivity to stress in relation to hyperactivity symptoms (Van West \& Debutte, 2009; Maldonado, Trianes, Cortés, Moreno, \& Escobar, 2009).

On the other hand, we find a correlation between BD and SS, leading us to inquire further into the relationship between stress and ADHD. Even though we could defend a bidirectional influence with regard to the different components that make up these two realities, we call attention to the perspective that postulates a third element that predisposes the mutual relationship of $\mathrm{BD}$ and SS. This third variable would be composed of problems, conflicts and maladjustments in their scholastic work and in social interaction with other students and teachers. In the age range that our research addresses, the realm of classmates and teachers makes up the relational world, outside of the family, in which the pupils interact. We maintain that there are certain risk factors and they exercise their influence during the developmental cycle of the ADHD child, giving rise to Behavior Disorders that can be detected later on. In this regard, the transactional approach postulates that there are certain temperament-determined behaviors that appear early on and constitute the developmental pillars of more complex, differentiated behaviors. The basic repertoire of socio-emotional behavior can predispose a "difficult child", such as a child with ADHD, to interact with others in unsatisfactory ways, creating cycles of social maladjustment (Kouzma \& Kennedy, 2004). The limited emotional regulation that is associated with ADHD provokes ineffective responses to stress and emotional outbursts, thereby constituting a risk factor for different Behavior Disorders (Lau, 2002). Another important predictor of behavior problems is the child's difficulty in sustaining attention during social interactions - an attentional disability also seen in our results of a correlation of SS with $\mathrm{AD}$ and $\mathrm{EFF}$ - due to the reduced efficacy of cognitive mechanisms that are required for finding solutions to problems (Oros \& Vogel, 2005). One recent contribution (Duncan, 1994) presents a synthesis of how psychopathologies relate to personal characteristics with highly negative emotionality (sadness, fear and frustration/anger) and low effortful control (attentional control and inhibitory control). Consequently, experiencing stressors related to the teaching-learning process has been associated with symptoms such as anxiety, increased tension, irritability, feelings of helplessness and insecurity, distrust and sadness (Hjern, Alfven \& Östberg, 2007), as well as a hostile attitude toward the school and the teachers (Trianes et al., 2009), and not being accepted and having fights with classmates (Oros \& Vogel, 2005; Lehman \& Repett, 2007). In summary, results confirm the importance of a child's stress-inducing characteristics as a risk factor in the course of ADHD (Colomer-Diago, Miranda-Casas, Herdoiza-Arroyo \& Presentación-Herrero, 2012). Taken together, these provide empirical evidence, within a leading line of research, that is demonstrating a relationship between psychopathology and personal characteristics such as high negative emotionality or low effortful control (Duncan et al., 1994).

Next, we consider the correlation of FS with AD (direct) and with ICI (inverse). The literature offers a comparison of stress-inducing characteristics that parents detect in their children, with and without ADHD (Lehman \& Repett, 2007), finding significantly higher values for the ADHD children in distraction, low adaptation, negative mood and demanding attitude. Other studies find that children with ADHD show a different profile of temperament and personality characteristics: lower means in effortful control, conscientiousness, benevolence and emotional stability; higher means in emotionality, activity and negative affect; and levels similar to the control group in shyness and extraversion (Escobar et al., 2008). Obviously, the parents' perception is imbued with the relational and emotional experience of having children with ADHD, in other words, with the family stress aspect, represented by the negative emotional impact experienced by the parents themselves.

Afterward, we attempted to relate academic performance with the rest of the parameters collected (signs of hyperactivity, self-perceived stress and attentional efficacy), by comparing their corresponding percentiles to the 
grades received in mathematics and language arts. These grades imply a ranked status (on a scale of 0-10), and represent an intragroup quantifier that cannot be ranked or compared across different years in school (see Table $3)$. Therefore, although the comparison between grades and percentiles does not imply the existence of an equivalent control group, both grades obtained and the standardized normative tables of the tests constitute the most suitable basis for inference, given that both are drawn up using the actual results from each respective age group (and what can be expected from them).

Table 3. Relationship between variable percentiles (ADHD/Stress) and academic results (percentiles)

\begin{tabular}{|c|c|c|c|c|c|c|c|c|c|c|}
\hline & 1 & 2 & 3 & 4 & 5 & 6 & 7 & 8 & 9 & 10 \\
\hline 1. Mathematics & 1.00 & & & & & & & & & \\
\hline 2. Language & $.801^{* *}$ & 1.00 & & & & & & & & \\
\hline 3. Hyperactivity & $-.365^{* *}$ & $-.357 * *$ & 1.00 & & & & & & & \\
\hline 4. Attention Deficit & $-.744 * *$ & $-.649 * *$ & $.576^{* *}$ & 1.00 & & & & & & \\
\hline 5. Behavior Disorder & $-.555^{* *}$ & $-.522 * *$ & $.705^{* *}$ & $.662 * *$ & 1.00 & & & & & \\
\hline $\begin{array}{l}\text { 6. Hyperactivity with } \\
\text { AD }\end{array}$ & $-.652 * *$ & $-.562 *$ & $.860^{* *}$ & $.884 * *$ & $.774 * *$ & 1.00 & & & & \\
\hline 7. Stress due to health & -.071 & -.102 & -.042 & .121 & .177 & .057 & 1.00 & & & \\
\hline 8. Academic Stress & $-.518^{* *}$ & $-.481 * *$ & .204 & $.514^{* *}$ & $.362 * *$ & $.402 * *$ & $.276^{*}$ & 1.00 & & \\
\hline 9. Family Stress & -.249 & -.175 & -.081 & .246 & .067 & .100 & $.295^{*}$ & $.448^{* *}$ & 1.00 & \\
\hline 10. Total Stress & $-.386^{* *}$ & $-.383 * *$ & .019 & $.422 * *$ & .263 & .259 & $.723 * *$ & $754 * *$ & $.695 * *$ & 1.00 \\
\hline
\end{tabular}

Together with the data shown in Table 3, a direct relationship between Attention efficacy and Mathematics ( $\mathrm{r}$ $=.566, \mathrm{p} \leq 0.01)$ and Language $(\mathrm{r}=.416, \mathrm{p} \leq 0.01)$ was also discerned, being opposite to the marks in Attention Deficit $(r=-.385, p \leq 0.01)$, Hyperactivity with Attention Deficit $(r=-.295, p \leq 0.05)$, Academic Stress $(r=$ $-.427, p \leq 0.01)$, Family Stress $(r=-.384, p \leq 0.01)$, Total Stress $(r=-.284, p \leq 0.05)$ and Impulse Control Index $(\mathrm{r}=-.536, \mathrm{p} \leq 0.01)$. On the other hand, a direct relationship between Impulse Control Index and Mathematics $(\mathrm{r}$ $=.360, \mathrm{p} \leq 0.05)$ was also discerned, being opposite to the marks in Hyperactivity $(\mathrm{r}=-.317, \mathrm{p})$ and Hyperactivity with Attention Deficit $(\mathrm{r}=-.303, \mathrm{p} \leq 0.05)$.

Firstly, the significant correlation found between mathematics and language arts grades at this age represents the adolescent's good overall performance as a student, where the demands have not yet reached a point that would reveal the student's specialization or limitation in a particular area or discipline. Results from both subjects present a negative correlation with all the symptoms linked to ADHD, confirming our expectations. Mathematical skill and linguistic abstraction depend on the functionality of higher cognitive processes, which are compromised by such phenomena as hyperactivity, impulsiveness and attentional disorders. Also confirmed was the direct correlation with EFF, for language arts, and with ICI and EFF, for mathematics. Even though good attentional aptitude (EFF) is important in both cases, impulse control (ICI) is more critical for mathematical thought, which is marked by the importance of cognitive processes such as working memory, problem solving, planning and deductive reasoning, all of which require to some extent a more sustained use of thought, rather than momentary use. These particular cognitive processes form part of the so-called executive functions, and are the most sophisticated mental capacities (Valiente-Barroso, Fernández-Guinea, \& García García, 2012). They develop progressively well into adolescence and youth, corresponding to the late maturity of the frontal lobe (Valiente-Barroso, 2011), and it has been well established that they are precisely the functions most affected in disorders that characterize ADHD (Castellanos \& Tannock, 2002). In our study, the correlation between age and EFF bears witness to an increase in attentional powers with age; both this fact and the increase in mathematics performance in direct relation to executive functionality (e.g., attentional capacity) are consistent with other studies that have been designed along these lines (Valiente-Barroso \& García García, 2013). In other words, to summarize the literature, we find that the connection that exists between grades in both subjects, teacher judgments about signs of ADHD and the objective efficiency shown for attentional capacity all point to the underlying role of executive functions. Furthermore, if the anomaly in these functions increases, warranting the 
diagnosis of execution dysfunction in addition to ADHD, it becomes more likely that such students will have to repeat a year in school, that they have a lower intelligence quotient and that they will be diagnosed for learning disability (Biederman et al., 2004; Miranda, Meliá \& Marco, 2009).

The mathematics grade, in turn, showed a negative correlation with the parameters of SS and TS, that is, low grades had a direct relationship with school stress and total stress. This data point would be justified, since, according to several studies, school stress is motivated by factors such as difficulty in carrying out academic tasks, test execution, school pressures, low school grades, in addition to problems interacting with teachers (Lehman \& Repett, 2007), which would logically be associated with the experience of low achieving students. Our results are consistent with previous studies that found a direct relationship between levels of stress in the adolescent student and low grades in Mathematics and Language Arts. Some of these studies also showed correlations between these parameters (stress and poor grades) and low levels of attitude, self-concept, and study strategies (Cabal-García \& Valiente-Barroso, 2012). In this way, the latter factors may be fulfilling a cause function (provoking academic deficits and/or the stress involved), a partial effect (being the consequence of the adolescent's mental dissipation produced by stress, and/or a decline in motivation produced by poor grades), synergy (multiplying the effect of stress itself on grades) or overlap (the content of any of these concepts overlapping with those that designate childhood stress or with those are evaluated de facto in certain class subjects). In any case, a feedback loop is plausible, where these factors, along with the traits of ADHD itself, may be mutually reinforcing.

From another perspective, we cannot overlook the attribution effect of teachers as a cause of their students' performance. As has been demonstrated, a more adaptive attributional style contributes to reduced levels of stress. Consequently, the teacher's attributional style influences toward improvement in the students' attributional system, which in turn contributes to improvement in school grades (Torre-Ramírez, \& Godoy-Ávila, 2002). This concept that the teacher holds with regard to his or her students, can: a) maximize or overrate the importance of small negative traits that are detected in a given student (e.g., assigning greater weight to mild behavior traits of inattention, behavior disorder, etc.); b) trigger a self-fulfilling prophecy, encouraging student behaviors similar to those that the teacher expects (e.g., impulsiveness and/or low grades, even though they may not necessarily be traits of ADHD or underlying stress); c) actually generate negative signs in line with the teacher's expectations (e.g., causing stress in the student, along with its associated negative consequences). This would offer us another approach to explaining the association and consistency between scores in $\mathrm{H}, \mathrm{AD}, \mathrm{BD}$ and $\mathrm{ADH}$ (teacher estimations) with the results for student stress, as well as his or her grades.

\section{Conclusions}

As a function of the results obtained and their interpretation, we confirm the validity of teachers' subjective judgment, or estimation, regarding the existence of ADHD signs in their students. On the other hand, a direct relationship is found between the student's perceived stress and signs of ADHD. This link would occur especially in students with a stronger inattention trait, where we expect greater reactivity to stress than what is detected in students with predominant hyperactivity. At the same time, an association appears between school stress and behavior disorder, which can be justified both by the mutual bi-directional influence of the two factors, and by the existence of predisposing factors, often found in the ADHD child, involving deficits in regulation of emotions and problems interacting with others (with school being the fundamental context for interaction at this age). We find in turn a direct relationship between academic performance, based on grades obtained in the subjects of mathematics and language arts, and objective attention capacity. The latter, as an executive function, constitutes a fundamental intellectual process for learning, and more specifically, for the degree of cognitive involvement that is required by these two subjects. On the other hand, more stress seems to be experienced by students with a deficit in mathematics achievement, possibly explained by the frustrating experiences that accompany school failure and distress, especially evident in the more demanding school subjects. Nor can we overlook the influence of each student's internal variables, such as self-concept, attitude and study strategies, or the effect of the teacher's concept of a given student in identifying maladaptive traits, modulating their grades and fostering their experience of stress. Furthermore, the importance of a loop of reciprocal influences could be postulated, helping to justify the link that is detected between ADHD traits, stress and academic performance. Future research should inquire further into these relations, as well as using a larger sample to increase the statistical power and inferential capacity of this study. Finally, we wish to underscore the implications that can be drawn from this work, for the purpose of optimizing our students' performance, and especially for raising awareness that would help us have greater consideration and greater capacity for detecting developmental problems, for the ultimate end of improving our students' quality of life. 


\section{Acknowledgement}

I wish to thank all participating children, parents, and teachers (Antares School, Cantabria, Spain).

\section{References}

Albert, J., López-Martín, S., Fernádez-Jaén, A. C., \& Carretié, L. (2008). Alteraciones emocionales en el trastorno por déficit de atención con hiperactividad: datos existentes y cuestiones abiertas. Revista de Neurología, 47, 39-45.

Alderson, R. M., Kasper, L. J., Hudec, K. L., \& Patros, C. H. (2013). Attention-deficit/hyperactivity disorder (ADHD) and working memory in adults: a meta-analytic review. Neuropsychology, 27(3), 287-302. http://dx.doi.org/10.1037/a0032371

American Psychiatric Association. (1994). Diagnostic and statistical manual of mental disorder (DSM IV) (4th ed.). Washington DC: American Psychiatric Association.

American Psychiatric Association. (2013). Diagnostic and Statistical Manual of Mental Disorders (DSM V) (5th ed.). Arlington, VA: American Psychiatric Publishing.

Bailly, D., Wertz, E., Devos, P., Veignie, L., \& Turck, D. (2004). Une mesure du stress des adolescents hospitalisés. Archives de Pédiatrie, 11(12), 1430-1437. http://dx.doi.org/10.1016/j.arc.ped.2004.07.027

Bakker, L., Rubiales, J., \& López, M. (2012). Percepción de estrés escolar y ritmo circadiano de cortisol en niños con TDAH. Archivos de Neurociencias, 17(1), 39-44.

Barkley, R. A. (1997). ADHD and the nature of self-control. New York: Guilford Press.

Barkley, R. (2006). Attention-Deficit Hyperactivity Disorder, Third Edition: A Handbook for Diagnosis and Treatment. New York: Guildford Press.

Biederman, J. (2005). Attention-deficit/hyperactivity disorder: A selective overview. Biological Psychiatry, 57(11), 1215-1220. http://dx.doi.org/10.1016/j.biopsych.2004.10.020

Biederman, J., Monuteaux, M. C., Doyle, A. E., Seidman, L. J., Wilens, T. E., Ferrero, F, et al. (2004). Impact of executive function deficits and attention deficit/hyperactivity disorder (ADHD) on academic outcomes in children. Journal of Consulting and Clinical Psychology, 72(5), 757-766. http://dx.doi.org/10.1037/0022-006X.72.5.757

Brown, T. E. (2005). Attention Déficit Disorder: The unfocused mind in children and adults. New Haven \& London: Yale University Press.

Cabal-García, P., \& Valiente-Barroso, C. (2012). Stress levels, academic performance and global academic approach in preteen students. In J. A. Gonzalez-Pienda, C. Rodríguez, D. Alvarez, R. Cerezo, E. Fernández, M. Cueli, T. García, E. Tuero, \& N. Suárez (Eds.), Learning Disabilities: Present and Future (pp. 1139-1146). Oviedo: Universidad de Oviedo.

Castellanos, F. X. (1997). Toward a pathophysiology of attention-deficit/hyperactivity disorder. Clinical Pediatrics (Philadelphia), 36(7), 381-393. http://dx.doi.org/10.1177/000992289703600702

Castellanos, F. X., \& Tannock, R. (2002). Neuroscience of attention-deficit/hyperactivity disorder: The search for endophenotypes. Nature Reviews Neuroscience, 3(8), 617-628. http://dx.doi.org/doi:10.1038/nrn896

Cak, H. T., Dinc, G. S., Tuzun, Z., Evinc, S. G., Cop, E., \& Cuhadaroglu Cetin, F. (2013). Comorbidity and continuity of attention deficit hyperactivity disorder (ADHD) from childhood to adolescence in Turkey. ADHD Attention Deficit and Hyperactivity Disorders, in press.

Colomer-Diago, C., Miranda-Casas, A., Herdoiza-Arroyo, P., \& Presentación-Herrero, M. J. (2012). Funciones ejecutivas y características estresantes de niños con trastorno por déficit de atención/hiperactividad: influencia en los resultados durante la adolescencia. Revista de Neurología, 54(S1), 117-126.

Duncan, G. J., Brooks-Gunn, J., \& Klebanov, P. K. (1994). Economic deprivation and early childhood development. Child Development, 65, 296-318. http://dx.doi.org/10.2307/1131385

Emond, V., Joyal, C., \& Poissant, H. (2009). Structural and functional neuroanatomy of attention-deficit hyperactivity disorder (ADHD). Encephale, 35(2), 107-114. http://dx.doi.org/10.1016/j.encep.2008.01.005

Escobar, M., Trianes, M. V., \& Fernández-Baena, F. J. (2008). Daily stress, sociometric status and emotional adjustment in primary school childen. In P. Roussi, E. Vassilaki, \& K. Kaniasty (Eds.), Stress and Psycosocial Resources (pp. 91-101). Berlin: Logos Verlag Berlin. 
Factor, P. I., Rosen, P. J., \& Reyes, R. A. (2013). The Relation of Poor Emotional Awareness and Externalizing Behavior Among Children With ADHD. Journal of Attention Disorders, in press.

Faraone, S. V., Perlis, R. H., Doyle, A. E., Smoller, J. W., Goralnick, J. J., Holmgren, M. A., \& Sklar, P. (2005). Molecular genetics of attention-deficit/hyperactivity disorder. Biological Psychiatry, 57(11), 1313-1323, http://dx.doi.org/10.1016/j.biopsych.2004.11.024

Farré, A., \& Narbona, N. (2010). Evaluación del trastorno por déficit de atención con hiperactividad. Madrid: Tea Ediciones.

Fernández, A., \& López, I. (2006). Transmisión de emociones, miedo y estrés infantil por hospitalización. International. Journal of Clinical and Health Psychology, 6, 631-645.

Flook, L., \& Fligni, A. J. (2008). Family and school spillover in adolescentes' daily lives. Child Development, 79(3), 776-787. http://dx.doi.org/10.1111/j.1467-8624.2008.01157.x

Govaerts, S., \& Grégoire, J. (2004). Stressful academic situations: Study on appraisal variables in adolescence. Revue Européenne de Psychologie Appliquée, 54(4), 261-271. http://dx.doi.org/10.1016/j.erap.2004.05.001

Grohol, J. (2013). DSM-5 Changes: Attention Deficit Hyperactivity Disorder (ADHD). Psych Central. Retrieved October 10, 2013, from http://pro.psychcentral.com/2013/dsm-5-changes-attention-deficit-hyperactivity-disorder-adhd/004321.html

Hanson, J. L., Chung, M. K., Avants, B. B., Rudolph, K. D., Shirtcliff, E. A., Gee, J. C., Davidson, R. J., \& Pollak, S. D. (2012). Structural Variations in Prefrontal Cortex Mediate the Relationship between Early Childhood Stress and Spatial Working Memory. The Journal of Neuroscience, 32(23), 7917-7925.

Hjern, A., Alfven, G., \& Östberg, V. (2007). School stressors, psychological complaints and psychosomatic pain. Acta Paediatrica, 97(1), 112-127. http://dx.doi.org/10.1111/j.1651-2227.2007.00585.x

Jose, P. E., \& Ratcliffe, V. (2004). Stressor frequency and perceived intensity as predictors of internalizing symptoms: Gender and age differences in adolescence. New Zealand Journal of Psychology, 33, 145-154.

Kalanthroff, E., Naparstek, S., \& Henik, A. (2013). Spatial processing in adults with attention deficit hyperactivity disorder. Neuropsychology, 27(5), 546-555. http://dx.doi.org/10.1037/a0033655

Kanner, A. D., Coyne, J. C., Schaefer, C., \& Lazarus, R. S. (1981). Comparison of two models of stress measurement: Daily hassles and uplifts versus major life events. Journal of Behavioral Medicine, 4, 1-39.

Lau, B. W. (2002). Does the stress in childhood and adolescence matter? A psychological perspective. The Journal of the Royal Society for the Promotion of Health, 122(4), 238-244. http://dx.doi.org/10.1177/146642400212200411

Lehman, B. J., \& Repett., R. L. (2007). Bad days don't end when the school bell rings: The lingering effectsof negative school events on children's mood, self-esteem, and perception of parent-child interaction. Social Development, 16(3), 596-618. http://dx.doi.org/10.1111/j.1467-9507.2007.00398.x

Lin, M. K., Freita, C. M., Schote, A. B., Pálmaso, H., Seitz, C., Renner, T. J., Romanos, M., Walitza, S., Jacob, C. P., Reif, A., Warnke, A., Cantor, R. M., Lesch, K. P., \& Meyer, J. (2013). Haplotype co-segregation with attention deficit-hyperactivity disorder in unrelated German multi-generation families. American Journal of Medical Genetics Part B: Neuropsychiatric. http://dx.doi.org/10.1002/ajmg.b.32192

Lupien, S. J., McEwen, B. S., Gunnar. M. R., \& Heim, C. (2009). Effects of stress throughout the lifespan on the brain, behaviour and cognition. Nature Reviews Neuroscience, 10, 434-445. http://dx.doi.org/10.1038/nrn2639

Maldonado, E. F., Trianes, M. V., Cortés, A., Moreno, E., \& Escobar, M. (2009). Salivary cortisol response to a psychosocial stressor on children diagnosed with Attention-Déficit/Hyperactivity Disorder: Differences between diagnostic subtypes. The Spanish Journal of Psychology, 12(2), 707-714. http://dx.doi.org/10.1017/S1138741600002079

Minzenberg, M. J. (2012). Pharmacotherapy for attention-deficit/hyperactivity disorder: From cells to circuits. Neurotherapeutics, 9(3), 610-621. http://dx.doi: 10.1007/s13311-012-0128-7

Miranda, A., Meliá, A., \& Marco, R. (2009). Habilidades matemáticas y funcionamiento ejecutivo de niños con trastorno por déficit de atención con hiperactividad y dificultades del aprendizaje de las matemáticas. Psicothema, 21, 63-69. 
Morán Sánchez, I., Navarro-Mateu, F., Robles Sánchez, F., \& Concepción Salesa, A. (2008). Validez del diagnóstico clínico de trastorno por déficit de atención con hiperactividad en las derivaciones de pediatría a la consulta de psiquiatría infantil. Atención Primaria, 40(1), 29-33. http://dx.doi.org/10.1157/13114322

Moulds, J. D. (2003). Stress manifestation in high school students: An Australian simple. Psychology in the Schools, 40, 391-402. http://dx.doi.org/10.1002/pits.10093

Nigg, J. T., \& Casey, B. J. (2005). An integrative theory of attention-déficit/ hyperactivity disorder based on the cognitive and affective neurosciences. Developmental and Psychopatology, 17(3), 785-806. http://dx.doi.org/10.1017/S0954579405050376

Oros, L. B., \& Vogel, G. K. (2005). Eventos que generan estrés en la infancia: Diferencias por sexo y edad. Enfoques, 17, 85-101.

Orvaschel, H., Lewinsohn, P. M., \& Seeley, J. R. (1995). Continuity of psychopathology in a community sample of adolescents. Journal of the American Academy of Child and Adolescent Psychiatry, 34(11), 1525-1535. http://dx.doi.org/ 10.1097/00004583-199511000-00020

Polanczyk, G., de Lima, S. M., Lessa Horta, B., Bierderman, J., \& Rohde, L. A. (2007). The worldwide prevalence of ADHD: A systematic review and metaregression analysis. American Journal of Psychiatry, 164, 942-948. http://dx.doi.org/ 10.1176/appi.ajp.164.6.942

Seiffge-Krenke, I. (2000). Causal links between stressful events, coping style and adolescent symptomatology. Journal of Adolescence, 23(6), 675-691. http://dx.doi.org/10.1006/jado.2000.0352

Seiffge-Krenke, I. (2007). Stress, coping and depression. Ponencia presentada en el Postgrado de Investigación en Procesos Básicos e Intervención en Psicología de la Salud, bienio 2006-2008, Universidad de Málaga, España.

Soliva-Vila, J. C. (2006). La disminución volumétrica del núcleo caudado derecho como fenotipo neuroanatómico del trastorno por déficit de atención con hiperactividad pediátrico (Tesis doctoral). Universitat Autònoma de Barcelona.

Thurstone, L. L., \& Yela, M. (2012). Test de percepción de diferencias (CARAS-R). Madrid: Tea Ediciones.

Torre-Ramírez, C., \& Godoy-Ávila, A. (2002). Influencia de las atribuciones causales del profesor sobre el rendimiento de los alumnos. Psicothema, 14(2), 444-449.

Trianes, M. V., Blanca, M. J., Fernández-Baena, F. J., Escobar, M., Maldonado, E. F., \& Muñoz, A. M. (2009). Evaluación del estrés infantil: Inventario Infantil de Estresores Cotidianos (IIEC). Psicothema, 21, 598-603.

Trianes, M. V., Blanca, M. J., Fernández-Baena, F. J., Escobar, M., \& Maldonado, E. F. (2011). Inventario de estrés cotidiano infantil. Madrid: Tea Ediciones.

Valdizán, J., Mercado, E., \& Mercado-Undanivia, A. (2007). Características y variabilidad clínica del trastorno por déficit de atención/ hiperactividad en niñas. Revista de Neurología, 44(2), 27-30.

Valiente-Barroso, C. (2011). Maduración ontogenética del córtex prefrontal y desarrollo de las funciones ejecutivas: consideraciones neurofuncionales en los procesos educativos. In J. M. Román Sánchez, M. A. Carbonero Martín, \& J. D Valdivieso Pastor (Eds.), Educación, aprendizaje y desarrollo en una sociedad multicultural (pp. 379-392). Madrid: Ediciones de la Asociación Nacional de Psicología y Educación.

Valiente-Barroso, C., Fernández-Guinea, S., \& García García, E. (2012). Introducción al Córtex Prefrontal y las Funciones Ejecutivas: conexiones entre Neurobiología y Cognición. In R. Quevedo-Blasco, \& V. J. Quevedo-Blasco (Eds.), Avances en Psicología Clínica (pp. 848-851). Granada: Asociación Española de Psicología Conductual (AEPC).

Valiente-Barroso, C., \& García García, E. (2013). Executive Function, Adolescent Development and Mathematical Competence: Importance of Quantitative and Qualitative Analysis in Educational Psychology. Procedia-Social and Behavioral Sciences, 69, 2193-2200. http://dx.doi.org/10.1016/j.sbspro.2012.12.185

Van West, D., \& Debutte, D. (2009). Differences in hypothalamic.pituitary-adrenal axis functioning among children with ADHD predominantly inattentive and combined types. European Child \& Adolescent Psychiatry, 18(9), 543-553. http://dx.doi.org/ 10.1007/s00787-009-0011-1

Vanaelst, B., De Vriendt, T., Huybrechts, I., Rinaldi, S., \& De nauw, S. (2012). Epidemiological approaches to measure childhood stress. Paediatric and Perinatal Epidemiology, 26, 280-297. http://dx.doi.org/10.1111/j.1365-3016.2012.01258.x 
Wagner, B. M., Compas, B. E., \& Howell, D. C. (1988). Daily and major life events: A test of an integrative model of psychosocial stress. American Journal of Community Psychology, 16(2), 189-205. http://dx.doi.org/10.1007/BF00912522

Wasserman, T., \& Wasserman, L. D. (2012). The sensitivity and specificity of neuropsychological tests in the diagnosis of attention deficit hyperactivity disorder. Applied Neuropsychology: Child, 1(2), 90-99. http://dx.doi.org/10.1080/21622965.2012.702025

\section{Copyrights}

Copyright for this article is retained by the author(s), with first publication rights granted to the journal.

This is an open-access article distributed under the terms and conditions of the Creative Commons Attribution license (http://creativecommons.org/licenses/by/3.0/). 